Editorial

\title{
Special Issue on Applications of Semiconductor Optical Amplifiers
}

\author{
Kyriakos E. Zoiros
}

Department of Electrical and Computer Engineering, Lightwave Communications Research Group, Democritus University of Thrace, Xanthi GR 67 100, Greece; kzoiros@ee.duth.gr; Tel.: +30-25410-79975

Received: 10 July 2018; Accepted: 18 July 2018; Published: 20 July 2018

\section{Introduction}

During recent years, the technology of semiconductor optical amplifiers (SOAs) has remarkably been evolving and has matured to the point that it presently is established as a key enabler for the development, implementation, optimization, and overall establishment of photonic circuits, subsystems, and networks (see indicatively [1-16]). Owing to the remarkable advancements that have been achieved in the field, SOAs are commercially available devices that exhibit several important properties, such as strong nonlinearities, low power consumption, wavelength flexibility, large dynamic range, fast response, broadband and versatile operation, small footprint, and capability for scalable integration in single chips at affordable cost [17]. These attractive characteristics have rendered SOAs core elements for the accomplishment of critical and indispensable tasks at fundamental [18] and system-oriented [19] level. Thus, SOAs have widely been adopted both by the research community and the industrial sector as a principal technological platform for the realization of a diverse range of applications with high performance.

\section{Special Issue Papers}

Following SOA's huge practical potential, this Special Issue was introduced and prepared with a two-fold aim: on one hand to address, present, and investigate modern applications of SOAs, while, on the other hand, to explore and highlight trends, challenges, and perspectives for motivating efforts toward continuous exploitation of these active modules in a feasible, innovative, and global manner. The submitted papers have successfully contributed to achieving these goals by treating cutting-edge topics that have led to the derivation, collection, and publication of significant results on SOA-enabled applications. In this manner, it has been possible, through reaching comprehensive conclusions, to advance knowledge and open new horizons in the target field of research. More specifically:

The research field of integrated optical memories is covered by C. Vagionas, P. Maniotis, S. Pitris, A. Miliou, and N. Pleros in Ref. [20]. This paper describes a novel application scenario of optical memories based on monolithically integrated SOA and Mach-Zehnder interferometer layouts/arrangements. In this context, it proposes an alternative path to circumvent the mismatch between the rapidly growing optical transmission line rates and the electronic processing speeds towards facilitating technological evolution in the era of the Internet of Things.

The use of SOAs for optical signal amplification applications is reported in two papers. Z.V. Rizou, K.E. Zoiros, and A. Hatziefremidis present in Ref. [21] a theoretical analysis and benchmarking of two basic optical notch filters employed to compensate for the SOA pattern effect. The comparison reveals the performance merits of each filter which allow it to favorably compete against the other for efficiently addressing the pattern-dependent operation of SOAs and assisting the latter in serving linear amplification applications with improved performance. S.P. Ó Dúill, P. Landais, and L.P. Barry propose in Ref. [22] multi-section SOAs as pre-amplifiers for short range optical communication links 
within datacenters. By creating and employing a simplified multi-section SOA model, they evaluate the performance benefits offered by these special type SOAs, which are shown to exhibit better input power dynamic range than conventional single-section SOAs when amplifying single- as well as multi-channel signals of advanced modulation format (4-level pulse amplitude modulation/PAM4).

Reflective semiconductor optical amplifiers (RSOAs) form the subject of two papers. S.A. Gebrewold, R. Bonjour, R. Brenot, D. Hillerkuss, and J. Leuthold in Ref. [23] conduct a comparative study of the capacity increase brought in Wavelength Division Multiplexing (WDM) passive optical networks (PONs) architectures by exploiting bit- and power-loading discrete multi-tone (DMT) modulation in upstream colorless transmitters using RSOAs. Three different RSOA-based schemes are compared against appropriate evaluation criteria whose measurement and analysis allows to specify and highlight performance and cost trade-offs. Concurrently, record high line rates in both back-to-back and transmission experiments are obtained and reported for all three configurations. Z.V. Rizou and K.E. Zoiros in Ref. [24] demonstrate the feasibility of using a single microring resonator (MRR) as optical notch filter for enabling RSOA direct modulation at extended data rate than is possible with the RSOA alone. To this aim, it has been investigated and specified how the MRR should be designed to improve the encoded signal characteristics for RSOA direct modulation applications.

The exploitation of SOAs for photonic switching purposes is addressed in two papers. N. Calabretta, W. Miao, K. Mekonnen, and K. Prifti in Ref. [25] present a novel photonic WDM optical cross-connect node based on SOAs that allows switching data signals in wavelength, space, and time for fully exploiting statistical multiplexing. Also, they report on the experimental assessment of this core building block for interconnecting network elements as well as computing and storage resources, which verifies the advantages of using SOAs to realize the WDM cross-connect switch in terms of transparency, switching speed, photonic integrated amplification for lossless operation, and gain equalization. R. Stabile in Ref. [26] reviews the current status of fast reconfigurable medium-scale Indium Phosphide (InP) integrated photonic switch matrices based on the use of SOA gates. The focus is on broadband and cross-connecting monolithic implementations that grant multi-input/output port and channel connectivity based on a packet-compliant SOA multi-stage switching matrix. The opportunities for increasing connectivity, enabling nanosecond-order reconfigurability, and introducing distributed optical power monitoring at the physical layer are highlighted. Furthermore, complementary architectures based on resonant switching elements developed on the same material platform for power efficient switching are considered. Lastly, performance projections related to the physical layer are presented, and strategies for improvements in view of opening a route towards large-scale power efficient fast reprogrammable photonic integrated switching circuits are discussed.

The leveraging of SOAs as nonlinear elements in the context of all-optical functionalities is treated by Y. Lin, A.P. Anthur, S. P. Ó Dúill, F. Liu, Y. Yu, and L.P. Barry in Ref. [27]. In particular a wavelength converter is developed, which is comprised of an SOA that takes advantage of four wave mixing (FWM) and a fast-switching sampled grating distributed Bragg reflector (SG-DBR) tunable laser as one of the pump sources. By studying phase noise issues in FWM as well as vector theory in SOAs in conjunction with a detailed characterization of the SGDBR laser, rapid and reconfigurable wavelength conversion is experimentally demonstrated on bursty/packet data of advanced modulation formats towards dynamic, adaptive, and bandwidth-efficient next generation transparent optical networks.

Finally, the research activity on Optical Code Division Multiple Access (OCDMA) is represented by M.S. Ahmed and I. Glesk in Ref. [28]. This paper explores the use of SOAs in the transmitter side of such a system based on multi-wavelength picoseconds code carriers for mitigation of temporal distortion of an OCDMA auto-correlation affected by the temperature induced dispersion changes in a fiber optic transmission link. To this aim, it is shown both experimentally and by simulations, that a distorted OCDMA auto-correlation due to the temperature-induced fiber dispersion can be corrected by manipulating the chirp of code carriers when traversing a biased SOA prior to entering the transmission link. 


\section{Submission and Review Process}

In this Special Issue, two types of submissions were sought: 'Regular', to ensure largest participation and dissemination, and 'Invited', to have experts communicate their in-depth and thorough know-how. A number of fee waivers in the form of 'Feature Paper' were additionally offered to attract outstanding 'Original Research' or 'Review' articles. After initial screening and pre-review approval by the Guest and Assistant Editors based on abstract/manuscript suitability, papers were reviewed by at least two independent reviewers with appropriate expertise in the field, which were chosen from Applied Sciences available database. The feedback, comments, and suggestions provided by reviewers and Editors helped authors improve their papers by making the necessary changes and incorporating them in their revised paper.

\section{Future Directions}

Following the Special Issue closure, more in-depth research using SOAs is foreseen to exploit them in applications such as direct signal amplification, external modulation, optical pulse generation and manipulation, all-optical signal processing, all-optical computing, all-optical combinational and sequential logic circuits, photonic switching fabrics, optical wireless communications, optical access networks, converged telecommunications networks, radio-over-fiber, microwave/terahertz photonics, optical interconnects, optical time division multiplexing, wavelength division multiplexing and optical code division multiple access systems and networks, advanced modulation formats, slow and fast light, optical test and measurement techniques, photonic integrated circuits, non-telecom (sensors, medical imaging), etc.

Funding: This Special Issue received no external funding.

Acknowledgments: I would like to express my thanks to the authors of all submitted papers for their contributions to this Special Issue, as well as to the reviewers for their devoted time and effort. I would also like to thank the Editorial team of Applied Sciences, and especially Senior Assistant Editor Jenny Li from MDPI Branch Office, Beijing, for all the support throughout this Special Issue.

Conflicts of Interest: The author declares no conflict of interest.

\section{References}

1. Ueno, Y.; Nakamura, S.; Tajima, K. Nonlinear phase shifts induced by semiconductor optical amplifiers with control pulses at repetition frequencies in the $40-160-\mathrm{GHz}$ range for use in ultrahigh-speed all-optical signal processing. J. Opt. Soc. Am. B 2002, 19, 2573-2589. [CrossRef]

2. Morito, K.; Ekawa, M.; Watanabe, T.; Kotaki, Y. High-output-power polarization-insensitive semiconductor optical amplifier. J. Lightwave Technol. 2003, 21, 176-181. [CrossRef]

3. Zimmerman, D.R.; Spiekman, L.H. Amplifiers for the masses: EDFA, EDWA, and SOA amplest for metro and access applications. J. Lightwave Technol. 2004, 22, 63. [CrossRef]

4. Dong, H.; Zhu, G.; Wang, Q.; Sun, H.; Dutta, N.K.; Jaques, J.; Piccirilli, A.B. Multiwavelength fiber ring laser source based on a delayed interferometer. IEEE Photonics Technol. Lett. 2005, 17, 303-305. [CrossRef]

5. Sun, H.; Wang, Q.; Dong, H.; Dutta, N.K. All-optical logic performance of quantum-dot semiconductor amplifier-based devices. Microwave Opt. Technol. Lett. 2006, 48, 29-35. [CrossRef]

6. Matsuura, M.; Kishi, N.; Miki, T. Broadband regenerative wavelength conversion and multicasting using triple-stage SOA-based wavelength converter. Opt. Lett. 2007, 32, 1026-1028. [CrossRef] [PubMed]

7. Matsuura, M.; Iwatsu, N.; Kitamura, K.; Kishi, N. Time-resolved chirp properties of SOAs measured with an optical bandpass filter. IEEE Photonics Technol. Lett. 2008, 20, 2001-2003. [CrossRef]

8. Ma, S.; Sun, H.; Chen, Z.; Dutta, N.K. High speed all-optical PRBS generation based on quantum-dot semiconductor optical amplifiers. Opt. Express 2009, 17, 18469-18477. [CrossRef] [PubMed]

9. Tan, H.N.; Matsuura, M.; Kishi, N. Enhancement of input power dynamic range for multiwavelength amplification and optical signal processing in a semiconductor optical amplifier using holding beam effect. J. Lightwave Technol. 2010, 28, 2593-2602. [CrossRef] 
10. Kravtsov, K.; Fok, M.P.; Rosenbluth, D.; Prucnal, P.R. Ultrafast all-optical implementation of a leaky integrate-and-fire neuron. Opt. Expr. 2011, 19, 2133-2147. [CrossRef] [PubMed]

11. Li, W.; Ma, S.; Hu, H.; Dutta, N.K. All optical latches using quantum-dot semiconductor optical amplifier. Opt. Commun. 2012, 285, 5138-5143. [CrossRef]

12. Spiekman, L.H. Active devices in passive optical networks. J. Lightwave Technol. 2013, 31, 488-497. [CrossRef]

13. Uenohara, H.; Aikawa, Y. A bit rate adaptable operation of a hybrid integrated wavelength converter using a semiconductor optical amplifier type Mach-Zehnder Interferometer. Opt. Lett. 2014, 38, 4982-4984. [CrossRef] [PubMed]

14. Chang, M.P.; Wang, N.; Wu, B.; Prucnal, P.R. Simultaneous variable optical weight and delay in a semiconductor optical amplifier for microwave photonics. J. Lightwave Technol. 2015, 33, 2120-2126. [CrossRef]

15. Perin, J.K.; Sharif, M.; Kahn, J.M. Sensitivity improvement in 100 Gbit/s-per-wavelength links using semiconductor optical amplifiers or avalanche photodiodes. J. Lightwave Technol. 2016, 33, 5542-5553. [CrossRef]

16. Volet, N.; Spott, A.; Stanton, E.J.; Davenport, M.L.; Chang, L.; Peters, J.; Briles, T.C.; Papp, S.B.; Diddams, S.A.; Meyer, J.; et al. Semiconductor optical amplifiers at 2.0- $\mu \mathrm{m}$ wavelength on silicon. Laser Photonics. Rev. 2017, 11, 1600165. [CrossRef]

17. Pleros, N.; Zakynthinos, P.; Poustie, A.; Tsiokos, D.; Bakopoulos, P.; Petrantonakis, D.; Kanellos, G.T.; Maxwell, G.; Avramopoulos, H. Optical signal processing using integrated multi-element SOA-MZI switch arrays for packet switching. IET Optoelectron. 2007, 1, 120-126. [CrossRef]

18. Rizou, Z.V.; Zoiros, K.E. SOA dynamics and pattern effects. In Handbook of Optoelectronic Device Modeling and Simulation: Fundamentals, Materials, Nanostructures, LEDs, and Amplifiers; CRC Press: Boca Ratón, FL, USA, 2017; Volume 1.

19. Zoiros, K.E. Semiconductor optical amplifier-based interferometric switches: Overview and characteristic applications of two main types. In Handbook of Interferometers: Research, Technology and Applications; Nova Publishers: Hauppauge, NY, USA, 2009; pp. 95-135.

20. Vagionas, C.; Maniotis, P.; Pitris, S.; Miliou, A.; Pleros, N. Integrated optical content addressable memories (CAM) and optical random access memories (RAM) for ultra-fast address look-up operations. Appl. Sci. 2017, 7, 700. [CrossRef]

21. Rizou, Z.V.; Zoiros, K.E.; Hatziefremidis, A. Comparison of basic notch filters for semiconductor optical amplifier pattern effect mitigation. Appl. Sci. 2017, 7, 783. [CrossRef]

22. Ó Dúill, S.P.; Landais, P.; Barry, L.P. Estimation of the performance improvement of pre-Amplified PAM4 systems when using multi-section semiconductor optical amplifiers. Appl. Sci. 2017, 7, 908. [CrossRef]

23. Gebrewold, S.A.; Bonjour, R.; Brenot, R.; Hillerkuss, D.; Leuthold, J. Bit- and power-loading-A comparative study on maximizing the capacity of RSOA based colorless DMT transmitters. Appl. Sci. 2017, 7, 999. [CrossRef]

24. Rizou, Z.V.; Zoiros, K.E. Theoretical analysis of directly modulated reflective semiconductor optical amplifier performance enhancement by microring resonator-based notch filtering. Appl. Sci. 2018, 8, 223. [CrossRef]

25. Calabretta, N.; Miao, W.; Mekonnen, K.; Prifti, K. SOA based photonic integrated WDM cross-connects for optical metro-access networks. Appl. Sci. 2017, 7, 865. [CrossRef]

26. Stabile, R. Towards large-scale fast reprogrammable SOA-based photonic integrated switch circuits. Appl. Sci. 2017, 7, 920. [CrossRef]

27. Lin, Y.; Anthur, A.P.; Ó Dúill, S.P.; Liu, F.; Yu, Y.; Barry, L.P. Fast reconfigurable SOA-based wavelength conversion of advanced modulation format data. Appl. Sci. 2017, 7, 1033. [CrossRef]

28. Ahmed, M.S.; Glesk, I. Application of semiconductor optical amplifier (SOA) in managing chirp of optical code division multiple access (OCDMA) code carriers in temperature affected fibre link. Appl. Sci. 2018, 8, 715. [CrossRef]

(c) 2018 by the author. Licensee MDPI, Basel, Switzerland. This article is an open access article distributed under the terms and conditions of the Creative Commons Attribution (CC BY) license (http:/ / creativecommons.org/licenses/by/4.0/). 